\title{
Recent Common Perspectives for Geriatric Medicine and Rehabilitation Medicine
}

Bando $\mathrm{H}^{1,2^{*}}$, Moriyasu $\mathrm{A}^{3,4}$, Murakami $\mathrm{M}^{5}$

${ }^{1}$ Tokushima University / Medical Research, Tokushima, Japan

${ }^{2} J a p a n$ Masters Athletics, Tokushima division, board, Tokushima, Japan

${ }^{3}$ Rehabilitation Research Group for body and heart in Shikoku, Kagawa, Japan

${ }^{4}$ Akiboshi Bright Star training rehabilitation center, Kagawa, Japan

${ }_{5}^{5} J a p a n$ Masters Athletics, Kagawa division, vice-president, Kagawa, Japan

Corresponding Author: Hiroshi Bando, MD, Ph.D., FACP ORCID ID

Address: Tokushima University / Medical Research, Nakashowa 1-61, Tokushima 770-0943 Japan; Tel: +81-90-31872485; E-mail: pianomed@bronze.ocn.ne.jp

Received date: 04 October 2020; Accepted date: 04 November 2020; Published date: 11 November 2020

Citation: Bando H, Moriyasu A, Murakami M. Recent Common Perspectives for Geriatric Medicine and Rehabilitation Medicine. J Health Care and Research. 2020 Nov 11;1(3):193-96.

Copyright (C) 2020 Bando H, Moriyasu A, Murakami M. This is an open-access article distributed under the Creative Commons Attribution License, which permits unrestricted use, distribution, and reproduction in any medium, provided the original work is properly cited.

\begin{abstract}
Geriatric medicine has similar points of view to rehabilitation medicine. They have common concept for stages as disease (disorder), impairment, disability, and handicap. WHO has announced International Classification of Functioning, Disability and Health (ICF). Comprehensive Geriatric Assessment (CGA) has been evaluated rather high in geriatric syndrome, such as sarcopenia, frailty and cognitive impairment. Frailty seems to be found approximately $10-14 \%$ for more than 65 years. Sarcopenia implies a situation that physical function is reduced by muscle loss. These are evaluated by the European Working Group on Sarcopenia in Older People (EWGSOP2) and Asian Working Group for sarcopenia (AWGS) criteria.
\end{abstract}

\section{Keywords}

Geriatric Medicine, Rehabilitation Medicine, International Classification of Functioning Disability and Health (ICF), Comprehensive Geriatric Assessment (CGA), Asian Working Group for Sarcopenia (AWGS), European Working Group on Sarcopenia in Older People (EWGSOP2)

\section{Abbreviations}

International Classification of Functioning, Disability and Health (ICF); Comprehensive Geriatric Assessment (CGA); Asian Working Group for Sarcopenia (AWGS); European Working Group on Sarcopenia in Older People (EWGSOP2)

Recently, elderly population in ratio has been increasing in developed countries such as Japan. Then, the necessity for geriatric medicine has been expected in the medical system. Various health and medical problems have emerged so far, which could be roughly divided into disease (disorder) or disability. They have been managed adequately along to the situations and countries [1]. 
On the other hand, various problems can be discussed from the viewpoint of rehabilitation medicine. WHO established the International Classification of Impairments, Disabilities and Handicaps (ICIDH) in 1980 [2]. Among them, three levels of the degree for disability classification have been widely recognized, which were impairment, disability, and handicap. After that, revisions were attempted due to various issues for long. Consequently, the new International Classification of Functioning, Disability and Health (ICF) was announced [3]. There would be difference between ICIDH and ICF. The former was a classification for "consequence of disease", targeting only the negative part of disability. On the other hand, the latter "ICF" has changed its classification to "components of health". It can cover everything related to human health, including the positive part of health in addition to the disability [3].

As mentioned above, both of geriatric medicine and rehabilitation medicine have similar aspects. In fact, the evaluation method has been often used as four stages degree of disease (disorder), impairment, disability, and handicap [4]. The goals are to extend health and longevity, early detection of disease or disability, adequate care and intervention, and to improve the QOL and ADL for any people. The author has been involved in gerontology, primary care medicine, psychosomatic medicine and integrated medicine for many years. Among them, I had been the chairman in the 8th annual conference of Japan Primary Care Association (JPCA) [5], which has 4500 attendees in May 2017. In these medical subspecialties, they have common characteristic aspects of a wide area of medical care, indicating biopsychosocial perspective [5].

From this perspective, comprehensive geriatric assessment (CGA) has been practical and useful [6]. CGA has included multidisplinary diagnosis and therapeutic process. It can identify psychosocial, medical, and functional capability of elderly people. Consequently, CGA can lead the development of coordinated scheme to increase general health with aging. This would be the crucial perspective in the light of geriatric practice. Among them, there are three components from biopsychosocial model. In other words, i) physical: basic ADL, Barthel Index and instrumental ADL as physical aspect, ii) psychiatric: geriatric depression scale (GDS15), mini-mental state examination (MMSE) and vitality index, iii) social or others: family, residence, care, economical state, community, nutrition, taking medicine, falling down, and so on [7]. The CGA has been the fundamental evaluation way and the detail method varies from hospital to hospital in each country. In recent society, people have received various stresses, leading psychosomatic problems. Therefore, functional independence measure (FIM) has been used for evaluating adequately for physical aspect and dementia state in daily life [8]. This is an applicable way to evaluate their ADL on a 7-point scale and setting a specific level of return to daily life from diseased condition [9].

Geriatric syndrome is known to have several clinical symptoms, such as frailty, sarcopenia, anorexia of aging as well as cognitive impairment [10]. There are the major causes of poor outcomes in elder people. The rapid geriatric assessment (RGA) is one of the screening tests for primary care doctors to be able to detect geriatric syndromes [11]. RGA measures sarcopenia, frailty, cognition, anorexia, and advanced directives. There has been a useful mnemonic for the check list. It is MEALS ON WHEELS, which stands for Medications, Emotional (depression), Alcoholism, Latelife paranoia, Swallowing disorders, Oral conditions, Nosocomial infections, Wandering, Hypertension, Enteral problems, Eating problems, Low cholesterol, Stones (cholecystitis) [11]. These procedures can lessen medical problems and hospitalization, and improve adequate care for our clinical practice [12].

If a problem should exist concerning ADL of the elderly, it can be roughly classified into two patterns considering the progress to that level. One is a pattern where the function is reduced like a stairway associated with some trigger events. This is seen in cerebrovascular accident. In such case, the severe degree of disease may influence whether the rehabilitation could be effective or not [13]. The other is a pattern where physical function gradually decreases with aging. This is observed when the 
muscle strength gradually decreases. It is often observed in some cases of frail or sarcopenia. Muscle strength can be reversible to some extent by continuing rehabilitation. In actual practice, both of sarcopenia and frailty can show some significant overlaps [14]. When illustrating the relationship by concentric circles, there are three circles. They are i) frailty, ii) sarcopenia (physical phenotype), iii) sarcopenia (multi-dementional phenotype) from inside to outside $[13,14]$.

Frailty is diagnosed by some guidelines such as Cardiovascular Health Study (CHS) $[15,16]$. From the research using CHS criteria, the ratio of frailty with $65<$ years would be $10-14 \%$ [17]. Nutritional status reveals close relationship to the onset and progression of frailty [18]. In addition, intervention studies on frailty have established useful significance of exercise therapy [19]. However, enough evidence for other treatments has not been found. This would become meaningful problems for developing the future research.

In contrast, sarcopenia implies a situation where physical function shows the reduction due to muscle loss [20]. Regarding the guideline of the sarcopenia in Asian countries, the Asian Working Group for sarcopenia (AWGS) has been formerly established [21]. AWGS criteria has been useful, and recently new AWGS criteria was presented in 2019, which was in line with some changes among the criteria of European Working Group on Sarcopenia in Older People (EWGSOP2) [22,23].

The diagnosis for sarcopenia has been compared in elder people by application of three definitions of the guidelines, which are the criteria of Japan Society of Hepatology (JSH), AWGS and EWGSOP2 [23].

In summary, geriatric medicine and rehabilitation medicine have occupied important position in the medical practice for the older people. As to evaluating disease (disorder), impairment, disability, and handicap, clinical application of CGA would be useful. The condition of sarcopenia and frailty can be assessed for the adequate management of the patient. Further research would be expected for the wellness in the older people.

\section{Funding}

This work has not been funded by any institution or organization.

\section{Conflict of Interest}

All authors have read and approved the final version of the manuscript. The authors have no conflicts of interest to declare.

\section{References}

[1] Espinoza SE, Quiben M, Hazuda HP. Distinguishing Comorbidity, Disability, and Frailty. Curr Geriatr Rep. 2018 Dec;7(4):201-209. [PMID: 30984516]

[2] Stucki G. International Classification of Functioning, Disability, and Health (ICF): a promising framework and classification for rehabilitation medicine. Am J Phys Med Rehabil. 2005 Oct;84(10):733-40. [PMID: 16205428]

[3] Prodinger B, Cieza A, Oberhauser C, Bickenbach J, Üstün TB, Chatterji S, Stucki G. Toward the International Classification of Functioning, Disability and Health (ICF) Rehabilitation Set: A Minimal Generic Set of Domains for Rehabilitation as a Health Strategy. Arch Phys Med Rehabil. 2016 Jun;97(6):875-84. [PMID: 26827829]

[4] Hughes K, Corcoran T, Slee R. Health-inclusive higher education: listening to students with disabilities or chronic illnesses. Higher Education Research \& Development. 2015 Nov;35(3):488-501.

[5] Japan Primary Care Association (JPCA). Available from: http://www2.c-linkage.co.jp/jpca2017/en/

[6] Pilotto A, Cella A, Pilotto A, Daragjati J, Veronese N, Musacchio C, Mello AM, Logroscino G, Padovani A, Prete C, Panza F. Three Decades of Comprehensive Geriatric Assessment: Evidence Coming From Different Healthcare Settings and Specific Clinical Conditions. J Am Med Dir Assoc. 2017 Feb 1;18(2):192.e1-e11. [PMID: 28049616]

[7] Conroy SP, Bardsley M, Smith P, Neuburger J, Keeble E, Arora S, Kraindler J, Ariti C, Sherlaw-Johnson C, Street A, Roberts H. Comprehensive geriatric assessment for frail older people in acute hospitals: the HoW-CGA mixed-methods study. Southampton (UK): NIHR Journals Library; 2019 Apr. (Health Services and Delivery Research, No. 7.15.) Available from: https://www.ncbi.nlm.nih.gov/books/NBK540056/

[8] Sanvezzo VM, Montandon DS, Esteves LS. 
Instruments for the functional assessment of elderly persons in palliative care: an integrative review. Revista Brasileira de Geriatria e Gerontologia. 2018 Oct;21(5):604-15.

[9] Yamamoto C, Momota T. Relationship between Comprehensive Geriatric Assessment and Medication Adherence among Home-Bound Elderly Stroke Survivors. Journal of Japan Society of Nursing Research. 2018;41(4):741-51.

[10] Rubenstein LZ. Evolving models of comprehensive geriatric assessment. J Am Med Dir Assoc. 2015 Jun 1;16(6):446-47. [PMID: 25843620]

[11] Morley JE, Adams EV. Rapid Geriatric Assessment. J Am Med Dir Assoc. 2015 Oct 1;16(10):808-12. [PMID: 2643386o]

[12] Gupta S, Perry JA, Kozar R. Transitions of Care in Geriatric Medicine. Clin Geriatr Med. 2019 Feb;35(1):45-52. [PMID: 30390983]

[13] Cruz-Jentoft AJ, Kiesswetter E, Drey M, Sieber CC. Nutrition, frailty, and sarcopenia. Aging Clin Exp Res. 2017 Feb;29(1):43-48. [PMID: 28155181]

[14] Samper-Ternent R, Reyes-Ortiz C, Ottenbacher KJ, Cano CA. Frailty and sarcopenia in Bogotá: results from the SABE Bogotá Study. Aging Clin Exp Res. 2017 Apr;29(2):265-72. [PMID: 27034288]

[15] Fried LP, Tangen CM, Walston J, Newman AB, Hirsch C, Gottdiener J, Seeman T, Tracy R, Kop WJ, Burke G, McBurnie MA; Cardiovascular Health Study Collaborative Research Group. Frailty in older adults: evidence for a phenotype. J Gerontol A Biol Sci Med Sci. 2001 Mar;56(3):M146-56. [PMID: 11253156]

[16] Satake S, Senda K, Hong YJ, Miura H, Endo H, Sakurai T, Kondo I, Toba K. Validity of the Kihon Checklist for assessing frailty status. Geriatr Gerontol Int. 2016 Jun;16(6):709-15. [PMID: 26171645]

[17] Collard RM, Boter H, Schoevers RA, Oude Voshaar RC. Prevalence of frailty in community-dwelling older persons: a systematic review. J Am Geriatr Soc. 2012 Aug;6o(8):1487-92. [PMID: 22881367]
[18] Tamaki K, Kusunoki H, Tsuji S, Wada Y, Nagai K, Itoh M, Sano K, Amano M, Maeda H, Hasegawa Y, Kishimoto H, Shimomura S, Shinmura K. The Relationship between Dietary Habits and Frailty in Rural Japanese Community-Dwelling Older Adults: Cross-Sectional Observation Study Using a Brief SelfAdministered Dietary History Questionnaire. Nutrients. 2018 Dec 14;10(12):1982. [PMID: 30558211] [19] Silva RB, Aldoradin-Cabeza H, Eslick GD, Phu S, Duque G. The Effect of Physical Exercise on Frail Older Persons: A Systematic Review. J Frailty Aging. 2017;6(2):91-96. [PMID: 28555710]

[20] Shinmura K. Cardiac Senescence, Heart Failure, and Frailty: A Triangle in Elderly People. Keio J Med. 2016 Jun 25;65(2):25-32. [PMID: 27170235]

[21] Chen LK, Liu LK, Woo J, Assantachai P, Auyeung TW, Bahyah KS, Chou MY, Chen LY, Hsu PS, Krairit O, Lee JS, Lee WJ, Lee Y, Liang CK, Limpawattana P, Lin CS, Peng LN, Satake S, Suzuki T, Won CW, Wu CH, Wu SN, Zhang T, Zeng P, Akishita M, Arai H. Sarcopenia in Asia: consensus report of the Asian Working Group for Sarcopenia. J Am Med Dir Assoc. 2014 Feb;15(2):95101. [PMID: 24461239]

[22] Makizako H, Nakai Y, Tomioka K, Taniguchi Y. Prevalence of sarcopenia defined using the Asia Working Group for Sarcopenia criteria in Japanese community-dwelling older adults: A systematic review and meta-analysis. Phys Ther Res. 2019 Nov 29;22(2):53-57. [PMID: 32015941]

[23] Saeki C, Takano K, Oikawa T, Aoki Y, Kanai T, Takakura K, Nakano M, Torisu Y, Sasaki N, Abo M, Matsuura T, Tsubota A, Saruta M. Comparative assessment of sarcopenia using the JSH, AWGS, and EWGSOP2 criteria and the relationship between sarcopenia, osteoporosis, and osteosarcopenia in patients with liver cirrhosis. BMC Musculoskelet Disord. 2019 Dec 26;20(1):615. [PMID: 31878909]

Keywords: Geriatric Medicine, Rehabilitation Medicine, International Classification of Functioning Disability and Health (ICF), Comprehensive Geriatric Assessment (CGA), Asian Working Group for Sarcopenia (AWGS), European Working Group on Sarcopenia in Older People (EWGSOP2) 